\title{
Seeking Standards of Health Informatics Education in Saudi Arabia
}

\author{
Adeeb Noor
}

\begin{abstract}
As an initial step towards diversifying Saudi Arabia economy, the kingdom is focusing on the development and improvement of all public services through technology especially the health sector to meet the standards of the western world. We discuss the progress of the health informatics education globally with the main focus on the Kingdom of Saudi Arabia. For this purpose, we survey all academic institutions with their levels of education and found that only $9 \%$ of the 109 academic institutions offered specific programs in Health Informatics. While we focus on Saudi Arabia, we also gather information on courses per AMIA identification for Saudi academic institutions.
\end{abstract}

Keywords: AMIA, Education, Health Informatics, Saudi Arabia.

\section{INTRODUCTION}

The professions of healthcare are composed of a vast and growing number of fields, many of which are ever-evolving and increasingly interdisciplinary. The broad efforts of the span of healthcare require a complex conglomeration of skills and knowledge that both generate and utilize a staggering network of biomedical data for the study, research, analysis, and administration of the maintenance and improvement of our quality of life. The undertaking of the management and leveraging of these resources has led to the developing, interdisciplinary field of Health Informatics [1-2]. Such is the ambiguity and breadth of this collection of fields that they have been referenced in practice and literature by many names and broken down by several organizations into a spectrum of subcategories in an attempt to classify their many faces, particularly regarding standards of education.

From these observations, we shift our focus to the Kingdom of Saudi Arabia (KSA) and obtaining education in Health Informatics by illuminating the current state of affairs, understanding the troubles being faced, and posing a perspective that could have broader implications. This study could prove enlightening to those wishing to understand the challenges being faced in the KSA with the implementation of nationwide standards of education in Health Informatics, whether they be students or prospects seeking education and accreditation, researchers tracking the progress of development of the fields of Health Informatics, or administrators seeking status and guidance for understanding and addressing the current state of affairs. Additionally, per the KSA Vision 2030 initiative, development of educational programs in Health Informatics fits squarely in the purview of the eHealth strategy of the Ministry of Health (MOH).

Revised Manuscript Received on November 08, 2019.

* Correspondence Author

Adeeb Noor, Faculty of Computing and Information Technology, King Abdulaziz University, Jeddah, Saudi Arabia.

\section{RELATED WORK}

Several studies have already begun exploring the Saudi health informatics education context. Noor [3] has recently showed the lack of using technology in healthcare in KSA. With regard education, Altwaijiri and Aldosari [4] published a paper proposing the creation of a master's program adaptation based on the programs of three universities in the USA, Canada, and Australia. While this effort was a notable and organized attempt at developing health informatics programs for a single university, the approach taken was one of wholesale adoption and adaptation of targeted foreign programs rather than identifying and weighing specific core competencies for robust development and future-proofing. Four other works [5-8] have demonstrated the importance of health informatics in learning and decision-making but without focusing on the development of specific health informatics programs. Asiri [9] published a brief overview of some health informatics programs offered by Saudi educational institutions and attempted to address the challenges faced in the KSA and the international community as health informatics education is improved. These efforts to address and advise based on current research are laudable, though there is still much room for other perspectives and no definitive solutions have yet surfaced. Fortunately, awareness is growing. Fallatah [10] published a work focusing on the need for collaboration and teamwork as a part of inter-professional education (IPE) in order to prevent medical errors and promote the advancement of healthcare in the KSA. This interdisciplinary and collaborative aspect of healthcare education, already well-recognized in the west, is beginning to make its way into the curricular programs of the KSA.

\section{METHOD}

Public resources were used whenever possible so as to replicate the experience a layperson seeking knowledge through government resources, official websites, and information officially or tangentially published on the public internet, and direct email and voice communications with those officially involved with the administration of the programs and courses. A sample was collected consisting of information gathered for programs and courses from 109 colleges and universities located throughout the KSA, 
including public, private, and military schools. For those schools found to have specific programs in Health Informatics, the availability of course offerings per the AMIA recommendations [11] were also examined

\section{RESULTS AND DISCUSSION}

Only 10 of the 109 academic institutions surveyed open ly offered programs specific to Health Informatics with most of them being bachelor's programs. Programs relat ed to medical coding appeared to have a disproportiona te prevalence. This is likely because medical coding is considered a certification path rather than only a course offered within a curriculum. Taking a look at those $10 \mathrm{p}$ rograms sheds some light on the similarities of the curricula of these programs with regards to AMIA and IMIA recommendations; it was found that on average e ach program offered half of the 22 courses, though whi ch courses of the 22 varied considerably by program $w$ ith only 6 of the courses being offered in 7 or more $p$ rograms. The minimum number of the 22 courses offere d by any program was 3 while the maximum number o ffered by any program was 20 . These minimal and max imal cases were extreme outliers with all remaining nu mbers of courses being heavily centered between 7 and 14.

Table 1 demonstrates the list of courses along with an indication of how many of the 10 universities off er each course

\begin{tabular}{|l|l|}
\hline Name of course & $\begin{array}{l}\text { Occurrences out of } \\
\text { universities }\end{array}$ \\
\hline Introduction to Health Informatics & 5 \\
\hline Public Health Informatics & 6 \\
\hline Electronic Health Records & 5 \\
\hline Coding System & 7 \\
\hline Research Methodology & 8 \\
\hline Epidemiology & 8 \\
\hline Biostatistics & 7 \\
\hline Data Mining & 3 \\
\hline Data Warehousing & 3 \\
\hline Decision Support System & 5 \\
\hline System Analysis and Design & 5 \\
\hline Computer Programing & 4 \\
\hline Database Management Systems & 7 \\
\hline Information Security & 6 \\
\hline Human Computer Interaction & 1 \\
\hline Health Promotion and Education & 4 \\
\hline Global Health & 3 \\
\hline Legal and Ethics in Health & 9 \\
\hline Informatics & 4 \\
\hline Health Economics & 1 \\
\hline Interdisplinary Perspectives & 5 \\
\hline Organization Behaviors & 2 \\
\hline Leadership in Healthcare & \\
\hline
\end{tabular}

The breadth of competencies that fit into the interdisciplinary fields of Health Informatics is vast and often difficult to specifically-label as pertinent to Health Informatics. The nature of Health Informatics, particularly regarding education, is still being decided and is ever evolving. In this study, it was found that only $9 \%$ of the 109 academic institutions surveyed in the KSA offered specific programs in Health Informatics. Also, there does not currently exist an extensive amount of published literature regarding the state of Health Informatics education in the KSA.

Despite efforts of standardization of accreditation at the international level per the IMIA of which the KSA is a member via the Saudi Association for Health Informatics (SAHI), the effects of such standardization require prioritization and time. As Health Informatics is an ever-evolving collection of fields, skills, and knowledge, it is necessary for the institutions of education to be constantly vigilant and maintain being apprised of current best practices. This observation was also supported by the lack of published literature regarding Health Informatics programs in the KSA. Hopefully, the information gathered and surveyed of existing curricula and programs will put similar awareness and focus on the state of Health Informatics education.

\section{CONCLUSION}

While standardization efforts have been made at the international level for identifying and classifying core competencies of Health Informatics at the graduate level, this is an ongoing process due to the relative newness as the defined conglomeration of fields and disciplines as well as the ever-changing skills and knowledge associated with managing and maintaining the well-being of humanity. The general lack of information and specifics to Health Informatics found from surveying 109 universities and colleges in the KSA owed partly to incomplete or missing descriptions of courses and programs on websites and other materials available to the public. It was not usually apparent within which department or program to search and attempts to contact departments for additional information were often misleading and inconclusive. If improvement is to be made, there needs to be prioritization and focus at the national and academic levels, especially researching and understanding developing core competencies of Health Informatics. Out of the 109 institutions surveyed, only 10 offered specific programs in Health Informatics with those programs only offering half of the 22 courses identified by AMIA on average.

\section{REFERENCES}

1. Kulikowski, C., Shortliffe, E., Currie, L., Elkin, P., Hunter, L., Johnson, T., Kalet, I., Lenert, L., Musen, M., Ozbolt, J., Smith, J., Tarczy-Hornoch, P. and Williamson, J. (2012). AMIA Board white paper: definition of biomedical informatics and specification of core competencies for graduate education in the discipline. Journal of the American Medical Informatics Association, 19(6), pp.931-938.

2. Fridsma, D. (2016). The scope of health informatics and the Advanced Health Informatics Certification. Journal of the American Medical Informatics Association, 23(4), pp.855-856.

3. Noor, A. (2019). The Utilization of E-Health in the Kingdom of Saudi Arabia. International Research Journal of Engineering and Technology. 6(9): 1229-1239.

4. Altwaijiri, M. and Aldosari, B. (2008). Health Informatics Master Program at King Saud bin Abdulaziz University for Health Sciences, Riyadh, Saudi 
Arabia. Yearbook of Medical Informatics, 17(01), pp.145-149.

5. Albarrak, A. Designing e-learning systems in medical education: A Case study. International Journal of Excellence in Healthcare Management. 2010 Jun;183(3119):1-9.

6. Albarrak, A.I. E-learning in medical education and blended learning approach. learning. 2011;13:14-20.

7. Househ, M.S., Saddik. B., and Al-Dosari. B. Development of a graduate level course in e-Health and Emerging Technology in Saudi Arabia. InITCH 2011 Feb 9 (pp. 69-73).

8. Bahkali, S., Almaiman, A., Almadani, W., Househ, M.S., and El Metwally, A. The state public health informatics in Saudi Arabia. InICIMTH 2014 Jul 24 (pp. 257-260).

9. Asiri, H. A. Challenges of the Health Informatics Education in the Kingdom of Saudi Arabia: What Stands in Our Way? Journal of Health Informatics in Developing Countries. 2014 Apr 8;8(1).

10. Fallatah, H. (2016). Introducing inter-professional education in curricula of Saudi health science schools: An educational projection of Saudi Vision 2030. Journal of Taibah University Medical Sciences, 11(6), pp.520-525.

11. Kampov-Polevoi, J. and Hemminger, B. "A curricula-based comparison of biomedical and health informatics programs in the USA." Journal of the American Medical Informatics Association, vol. 18, no. 2, pp.195-202, 2011. 